\title{
M-Brucin, an antibacterial peptide against Staphylococcus epidermidis and Streptococcus pyogenes
}

\author{
Thakorn Sornwatana", Teerakul Arpornsuwan'2, Sittiruk Roytrakul ${ }^{3}$, Nuanchawee Wetprasit ${ }^{4}$ \\ 'Department of Biochemistry, Faculty of Science, Mahidol University, Bangkok, Thailand. \\ ${ }^{2}$ Deparment of Medical Technology, Faculty of Allied Health Sciences, Thammasat University, Pathumthani. \\ ${ }^{3}$ National Center for Genetic Engineering and Biotechnology, National Science and Technology Development Agency (NSTDA), Pathum Thani, Thailand. \\ ${ }^{4}$ Department of Biotechnology, Faculty of Science, Ramkhamhaeng University, Bangkok, Thailand.
}

\begin{tabular}{l}
\hline ARTICLE INFO \\
\hline Article history: \\
Received on: 19/06/2017 \\
Accepted on: 21/12/2017 \\
Available online: 27/02/2018 \\
\hline Key words: \\
M-Brucin, Brucin, antibacte- \\
rial activity, S. pyogenes, $S$. \\
epidermidis.
\end{tabular}

\begin{tabular}{|c|}
\hline ABSTRACT \\
\hline $\begin{array}{l}\text { Brucin, a plant-derived specific antibacterial peptide against } S \text {. pyogenes was chemically synthesized and its amino } \\
\text { acid sequence, } \mathrm{NH}_{2}-H i s \text {-Thr-Leu-Cys-Met-Asp-Gly-Gly-Ala-Thr-Tyr} \text {, was modified to improve the antibacterial } \\
\text { activity. Only one from five-modified peptides with the sequence } \mathrm{NH}_{2}-H i s-T h r \text {-Leu-Cys-Met-Gly-Lys-Ala-Thr-Tyr} \\
\text { possessed the antibacterial activity and it was designated as "M-Brucin". Structural analysis of M-Brucin indicaed } \\
\text { that it was a random coil peptide with a molecular mass of } 1248.43 \mathrm{Da} \text {. It was a positive charge peptide (net charge }= \\
+1 \text { ) with a pI value of } 8.21 \text { and hydrophobicity ratio of } 40 \% \text {. The positive antimicrobial effect of M-Brucin was tested } \\
\text { by agar dilution technique against } 30 \text { human-pathogenic bacteria and } 1 \text { fungus. Its inhibitory activity was against } \\
\text { S. epidermidis and } S \text {. pyogenes DMST } 17020 \text { with } \mathrm{IC}_{50} \text { values of } 225 \mu \mathrm{M} \text { and } 250 \mu \mathrm{M} \text {, respectively. Moreover, its } \\
\text { inhibitory activity was identified as being as strong as penicillin } \mathrm{G} \text { and chloramphenicol, with no toxicity to normal } \\
\text { Vero cells. The results suggest that M-Brucin could be purposed for further development as a new drug to specific } \\
\text { treatment of various human bacterial infectious diseases. }\end{array}$ \\
\hline
\end{tabular}

\section{INTRODUCTION}

Antimicrobial peptides (AMPs) are typically rich in hydrophobic residues, including Leu, Ile, Val, Phe and Trp, and they usually have an excess of cationic amino acids, which confers a net positive charge (Hancock and Haney, 2013). In the presence of phospholipid membranes, these properties allow AMPs to adopt diverse amphipathic structures, which can be separated into four broad structural classes: $\alpha$-helical, $\beta$-sheet, extended conformation and looped peptides containing disulfide bridges (Hancock and Haney, 2013). Staphylococcus epidermidis and Streptococcus pyogenes are Gram-positive cocci bacteria that cause various infectious diseases. Especially, S. Pyogenes (group A streptococus, GAS) causes severe clinical diseases with high risk death. The diseases caused by GAS can be found from superficial infections to invasiveness for example pharyngitis, scarlet fever,

\section{"Corresponding Author}

Thakorn Sornwatana, Department of Biochemistry, Faculty of Science, Mahidol University, Bangkok, Thailand 10400.

E-mail: thakorn.sor@mahidol.ac.th impetigo, erysipelas, cellulitis and necrotizing fasciitis (Carapetis et al., 2005; Mitchell, 2003). S. epidermidis is the most prevalent species of the coagulase-negative staphylococci, accounting for $65 \%$ to $90 \%$ of all staphylococci recovered from the blood. It is an important opportunistic pathogen causing nosocomial infections (Michael, 2009) and plays an important role in nosocomial bacteremia symptoms in humans, having a multidrug-resistant pattern, including resistance to methicillin (Weinstein et al., 1997). Brucin is a potent antibacterial peptide specific to S. pyogenes, produced from the dried fruit protein of Brucea javanica (L.) Merr. (Sornwatana et al., 2013). It comprises 11-amino acids with the sequence $\quad \mathrm{NH}_{2}$-His-Thr-Leu-Cys-Met-Asp-Gly-Gly-Ala-Thr-Tyr (HTLCMDGGATY), and extended with a random coil primary structure. At physiological $\mathrm{pH}$, it possesses a neutral charge and $36 \%$ hydrophobicity. Methods of rational design peptides aim to create novel peptides with improved antimicrobial activity and lower toxicity to human cells. These methods seek to reduce size, add selectivity and/or increase activity (William et al., 2012), since an increase in the peptide hydrophobicity often increases antimicrobial activity (Rosenfeld et al., 2010) and electrostatic 
interaction promotes the adsorption of AMPs onto the microbial membrane (Nikken et al., 2013). In this study, a sequence template method was used to design Brucin derivatives by database prediction. We have designed a number of structurally modified peptides from Brucin to improve its antimicrobial activity. The
modified-Brucin peptides were tested for bacterial inhibitory activity against selected human-pathogenic micro-organisms, and were compared to the original Brucin peptide. It was found that only one from the five modified Brucin peptides showed active antibacterial activity and we designated it as M-Brucin.

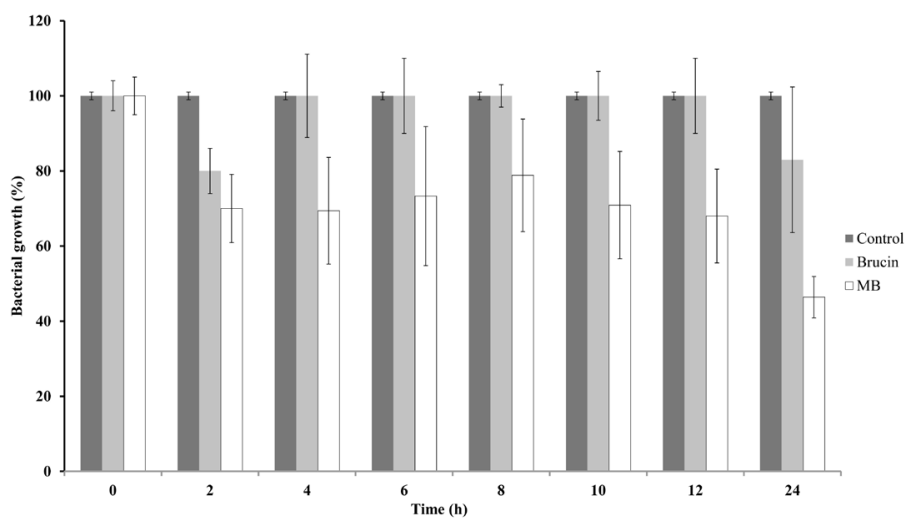

Fig. 1: Time course of two chemically synthesized peptides $(250 \mu \mathrm{mol} / \mathrm{L}$ each $)$ against the growth of $S$. epidermidis ATCC12228, Data are presented as the mean \pm SD of three independent assays, $\mathrm{p}=0.0002$.

\section{MATERIALS AND METHODS}

\section{Antibacterial peptide}

Brucin (original peptide) and modified-Brucin peptides were purchased from GL Biochem Shanghai Ltd., China. The peptides were synthesized according to the manufacturer's protocol. The peptides were purified after deprotection by using HPLC (OSD $\mathrm{C}_{18}$ reverse-phase HPLC column). The modifiedBrucin peptides were designed to change net charge and to increase the hydrophobicity ratio of the original Brucin, as in the following sequences: $\mathrm{NH}_{2}-H i s-T h r-L e u-C y s-M e t-A s p-L y s-$ Lys-Ala-Thr-Tyr, $\quad \mathrm{NH}_{2}$-His-Thr-Leu-Cys-Met-Asp-Arg-Arg-AlaThr-Tyr, $\quad \mathrm{NH}_{2}$-His-Thr-Leu-Cys-Met-Asp-Pro-Pro-Ala-Thr-Tyr, $\mathrm{NH}_{2}$-His-Thr-Leu-Cys-Met-Gly-Lys-Ala-Thr-Tyr and $\mathrm{NH}_{2}$-HisThr-Leu-Cys-Met-Gly-Gly-Ala-Thr-Tyr.

\section{Antimicrobial activity test}

Antimicrobial activities of the original peptide, Brucin and five modified-Brucin peptides were determined by broth dilution method and the recommendation from Clinical and Laboratory Standard Institute (NCCLS, 1997). Details of the methods were followed by Sornwatana et al. (2013). Three independent experiments were monitored. Growth inhibitory activity of the peptide was determined by $\%$ Growth inhibition = 1 - [(OD peptide treated - OD blank)/(OD control - OD blank)] $\times 100$ and $\mathrm{IC}_{50}$ value was calculated from the lowest concentration producing inhibitory activity $50 \%$ of microbial growth in comparison to positive control with no inhibitory activity.

\section{Cytotoxicity test against Vero cell line}

The cytotoxicity effects of the modified-Brucin peptides against a normal cell line, African green monkey kidney (Vero) cells were performed by 3-(4,5-dimethylthiazol-2-yl)-2,5diphenyltetrazolium bromide (MTT) assay (Ferrari et al., 1990). Details of method were followed by Arpornsuwan et al. (2006).
The $0.01 \%$ DMSO was added to each OD control at the same concentration as used in the corresponding peptide-treated wells. The cytotoxicity was calculated as following:

$$
\% \text { Cytotoxicity }=1-[(\mathrm{OD} \text { peptide treated }- \text { OD blank }) /
$$

$(\mathrm{OD}$ control - OD blank $)] \times 100$.

\section{Structural analysis and database screening of modified peptides}

Each modified peptide was identified a secondary structure by using the GOR secondary structure prediction method, version IV (Garnier et al., 1996). The sequence of the peptide was matched by the APD (Antimicrobial Peptide Database) (Wang et al., 2009) (http://aps.unmc.edu/AP/). The physicochemical parameters of modified peptides were computed using the bioinformatics programs ProtParam (http://www.expasy. ch/tools/protparam.html).

\section{Structure characterization by circular dichroism}

CD spectra of the modified peptide, M-Brucin was performed as described below. The peptide was dissolved in $10 \%$ SDS in distilled water to a final concentration of $0.2 \mathrm{mg} / \mathrm{ml}$ to form anionic micelles (Sangtanoo et al., 2014). The spectra of the peptide were measured by JASCO CD, model J-815 at room temperature in 1-mm path length quartz cell with the scanning speed of $50 \mathrm{~nm} / \mathrm{min}$ from 190-260 $\mathrm{nm}$. Each spectrum was the average of three scans. Details of method were followed by Lingeng et al. (2012).

\section{Statistical analyses}

The antibacterial activities of the modified peptides of treatment groups and controls were compared using two-way analysis of variance (ANOVA). Differences between groups were considered to be significant at a $\mathrm{P}$-value of $<0.05$. Statistical analyses were performed with GraphPad Prism 5.04 (GraphPad Software, Inc.). 
Table 1: Minimum inhibitory concentration of Brucin and modified Brucin (MB) against human pathogenic microbs.

\begin{tabular}{|c|c|c|}
\hline \multirow{2}{*}{ Microbes } & \multicolumn{2}{|c|}{$\mathrm{MIC}(\mu \mathrm{mol} / \mathrm{L})$} \\
\hline & Brucin & MB \\
\hline 1. Acinetobacter anitratus (DMST 4183) & - & - \\
\hline 2. Acinetobacter baumannii (ATCC 19066) & - & - \\
\hline 3. Acinetobacter calcoaceticus (ATCC 23055) & - & - \\
\hline 4. Acinetobacter lwoffii (ATCC 15309) & - & - \\
\hline 5. Bacillus cereus (ATCC 11778) & - & - \\
\hline 6. Burkholderia cepacia (ATCC 25416) & - & - \\
\hline 7. Enterococcus faecalis (ATCC 29212) & - & - \\
\hline 8. Escherichia coli (ATCC 25922) & - & - \\
\hline 9. Pseudomonas aeruginosa (ATCC 27853) & - & - \\
\hline 10. Pseudomonas fluorescens (DMST 6034) & - & - \\
\hline 11. Salmonella enteritidis (ATCC 17368) & - & - \\
\hline 12. Salmonella typhi (DMST 5784) & - & - \\
\hline 13. Shigella dysenteriae (DMST 15111) & - & - \\
\hline 14. Staphylococcus aureus (ATCC 25923) & - & - \\
\hline 15. Staphylococcus aureus (MRSA) (DMST 20654) & - & - \\
\hline 16. Staphylococcus epidermidis (ATCC 12228) & - & 250 \\
\hline 17. Streptococcus agalactiae (DMST 17129) & - & - \\
\hline 18. Streptococcus pyogenes (DMST 17020) & 50 & 250 \\
\hline 19. Vibrio cholerae nonO1, nonO139 (DMST 2873) & - & - \\
\hline 20. Vibrio cholerae O139 (ATCC 51394) & - & - \\
\hline 21. Klebsiella pneumoniae (ATCC 27736) & - & - \\
\hline 22. Klebsiella oxytoca (DMST 16071) & - & - \\
\hline 23. Bacillus subtilis (ATCC 6633) & - & - \\
\hline 24. Escherichia coli O157, H7 (DMST 12743) & - & - \\
\hline 25. Listeria monocytogenes (DMST 17303) & - & - \\
\hline 26. Proteus mirabilis (DMST 8212) & - & - \\
\hline 27. Serratia marcescens (ATCC 8100) & - & - \\
\hline 28. Shigella flexneri (DMST 4423) & - & - \\
\hline 29. Shigella sonnei (group D) (DMST 2982) & - & - \\
\hline 30. Shigella boydii (DMST 7776) & - & - \\
\hline 31. Candida albicans (ATCC 10231) & - & - \\
\hline
\end{tabular}

- = No inhibition at a maximum peptide concentration tested $(500 \mu \mathrm{mole} / \mathrm{L})$.

\section{RESULTS}

\section{Antimicrobial activity of the modified peptides}

One approach to improve the antibacterial activity of a peptide was to increase net positive charge and/or hydrophobicity on the peptide molecule. In this study, the antibacterial peptide, Brucin ( $\mathrm{NH}_{2}$-His-Thr-Leu-Cys-Met-Asp-Gly-Gly-Ala-Thr-Tyr $)$ which is specific to $S$. pyogenes was chemically synthesized and its net charge was changed by deleting or replacing some negatively charge amino acids. Five modified peptides were designed (Table 2) and determined for the antimicrobial activity against 30 humanpathogenic bacteria and 1 fungus (Table 1). However, only a modified peptide of 10 amino acids of sequence $\mathrm{NH}_{2}-\mathrm{His}$-Thr-LeuCys-Met-Gly-Lys-Ala-Thr-Tyr, named M-Brucin demonstrated inhibitory activity against $S$. pyogenes and $S$. epidermidis with an $\mathrm{IC}_{50}$ values of $250 \mu \mathrm{M}$ and $225 \mu \mathrm{M}$, respectively (Figure 2A,
Figure 2B and Table 2). While, other modified peptides were inactive against all tested microorganisms (Table 1). The $\mathrm{IC}_{50}$ value of M-Brucin to $S$. pyogenes was 5 times lower than that of its original peptide, Brucin $(50 \mu \mathrm{M})$. Interestingly, the inhibitory activity of M-Brucin was as potent as two commercial antibiotic drugs, penicillin G and chloramphenicol (Table 2).

\section{Cytotoxicity of M-Brucin}

The effects of the modified peptide, M-Brucin and the original peptide, Brucin on the cell viability of Vero cells were examined by MTT assay (Figure 2C). Over the concentration tested, both peptides exerted no cytotoxicity against the Vero cells. The result implied that even the modified peptide, M-Brucin was able to inhibit some bacterial growth, it did not cause adverse side effects to the normal cells.

\section{Structural analysis and characteristic of M-Brucin}

Secondary structure of M-Brucin was studied in comparison to its original peptide Brucin by the GOR secondary structure prediction method, version IV in which $10 \%$ SDS represented the prokaryotic cell membrane (anionic micelles) (Sangtanoo et al., 2014). M-Brucin peptide was found to be non $\alpha$-helical structure in $10 \%$ SDS micells (No $\alpha$-helical was shown in the primary structure; Figure 3). Both peptides, M-Brucin and Brucin were found to have random coil structures. M-Brucin had a molecular mass of 1124.35 Da with pI value of 8.21 , net charge of +1 and hydrophobicity ratio of $40 \%$. Brucin had a molecular mass of 1168.31 Da with pI value of 5.08, net charge of -1 and hydrophobicity ratio of $36 \%$. The sequence analysis of M-Brucin and Brucin compared to other antimicrobial peptides in the AMPs database (Wang et al., 2009) indicated that M-Brucin and Brucin sequences were $45.5 \%$ and $41.6 \%$ similar to Sequin. M-Brucin ( $\mathrm{NH}_{2}$-His-Thr-Leu-Cys-Met-Gly-Lys-Ala-Thr-Tyr) was modified from the peptide Brucin ( $\mathrm{NH}_{2}-H i s-T h r-L e u-C y s-M e t-$ Asp-Gly-Gly-Ala-Thr-Tyr) by removal of the negatively charged amino acid, aspartate (Asp) and replacing a glycine (Gly) with the positively charged amino acid, lysine (Lys). The increase in net positive charge (from -1 to +1 ) and hydrophobicity ratio of M-Brucin (from $36 \%$ to $40 \%$ ) caused its specific antibacterial activity against the gram-positive bacteria, $S$. epidermidis and $S$. pyogenes.

\section{DISCUSSION}

At present, many antimicrobial peptide were identified and have known the general characteristics (Jenssen et al., 2006). Many peptides with less than 40 amino acid residues, cationic charge, folding structure, hydrophobic and hydrophilic molecules have been demonstrated to have potent antimicrobial activity (Shai, 2002; Yeamn and Yount, 2003; Godballe et al., 2011). Amphipathic structures have been shown to be more important than their general secondary structures in some antibacterial peptides (Wong and $\mathrm{Ng}$, 2005). However, only few peptides with unique antibacterial activities against Gram-positive bacteria have been found. For example, an antibacterial peptide, isoform 5 isolated from hemolymph of the immunized larvae of the Udo longicorn beetle, Acalolepta luxuriosa was shown to inhibit the growth of a gram-positive bacterium, Micrococcus luteus and a fungus, Magnaporthe grisea (Imamura et al., 2009). 
(A)

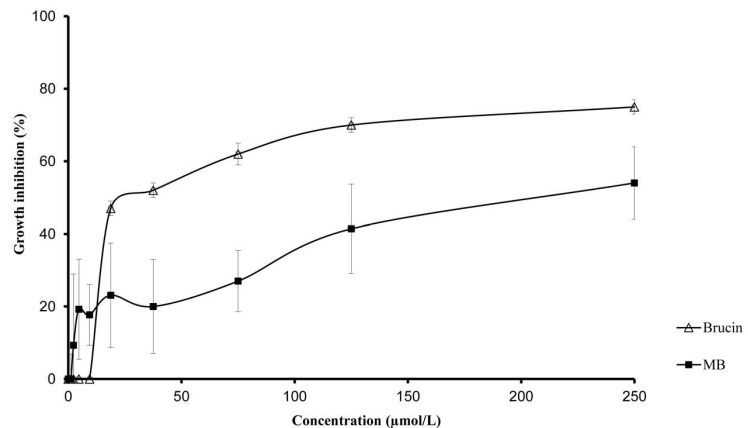

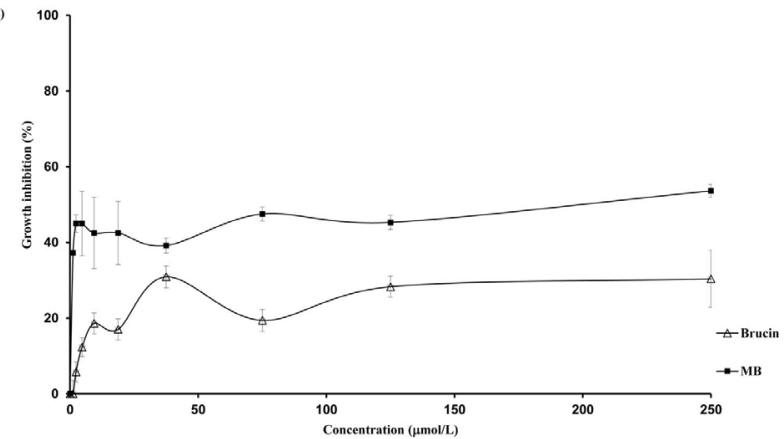

(C)

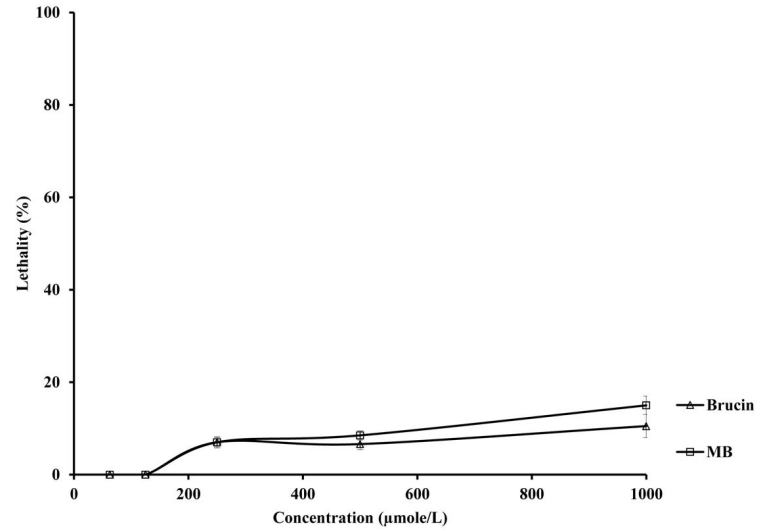

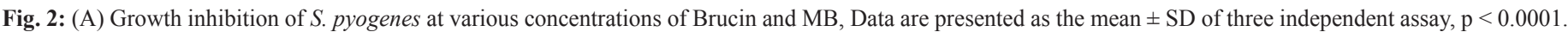

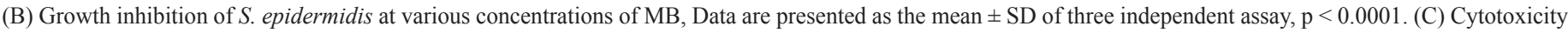
against Vero cell line at various concentration of Brucin and MB, Data are present as the mean $\pm \mathrm{SD}$ of three independent assay, $\mathrm{p}=0.0336$.

Table 2: Antibacterial activity of the synthetic peptides Brucin and modified Brucin (MB) against S. epidermidis and S. pyogenes.

\begin{tabular}{|c|c|c|c|c|c|}
\hline \multirow{2}{*}{ Peptide } & \multirow{2}{*}{ net charge } & \multirow{2}{*}{ Hydrophobicity ratio } & \multirow{2}{*}{ Mass (dalton) } & \multirow{2}{*}{$\frac{\mathrm{IC}_{50}(\mu \mathrm{mol} / \mathrm{L})}{\text { against } S . \text { epidermidis }}$} & \multirow{2}{*}{$\frac{\mathrm{IC}_{50}(\mu \mathrm{mol} / \mathrm{L})}{\text { against } S . \text { pyogenes }}$} \\
\hline & & & & & \\
\hline $\mathrm{NH}_{2}-H i s-T h r-L e u-C y s-M e t-A s p-L y s-L y s-A l a-T h r-T y r$ & +1 & 36 & 1310.55 & $-\mathrm{a}$ & $-\mathrm{a}$ \\
\hline $\mathrm{NH}_{2}-H i s-T h r-L e u-C y s-M e t-A s p-A r g-A r g-A l a-T h r-T y r$ & +1 & 36 & 1366.58 & $-b$ & $-b$ \\
\hline $\mathrm{NH}_{2}$-His-Thr-Leu-Cys-Met-Asp-Pro-Pro-Ala-Thr-Tyr & -1 & 36 & 1248.43 & $-\mathrm{c}$ & $-\mathrm{c}$ \\
\hline $\mathrm{NH}_{2}-H i s-T h r-L e u-C y s-M e t-G l y-L y s-A l a-T h r-T y r(\mathrm{M}-\mathrm{Brucin})$ & +1 & 40 & 1124.35 & 225 & 250 \\
\hline $\mathrm{NH}_{2}$-His-Thr-Leu-Cys-Met-Asp-Gly-Gly-Ala-Thr-Tyr (Brucin) & -1 & 36 & 1168.31 & $-d$ & 25 \\
\hline $\mathrm{NH}_{2}-$ His-Thr-Leu-Cys-Met-Gly-Gly-Ala-Thr-Tyr & 0 & 40 & 1053.22 & $-\mathrm{e}$ & $-d$ \\
\hline Penicillin G & & & 372.48 & 320 & 320 \\
\hline Chloramphenicol & & & 323.13 & 250 & 250 \\
\hline
\end{tabular}

$*_{-a},-b,-c,-d,-e=$ no inhibition at a maximum peptide concentration tested $(500 \mu \mathrm{mol} / \mathrm{L}), \mathrm{IC}_{50}=$ The half maximal inhibitory concentration.

M-Brucin, a modified peptide from Brucin is a new candidate specific antibacterial peptide against two Gram-positive bacterial, S. pyogenes and S. epidermidis. Both $S$. pyogenes and $S$. epidermidis are important human pathogens that cause a variety of diseases. M-Brucin is a short-chain 10-amino acid peptide $\left(\mathrm{NH}_{2}-\right.$ His-Thr-Leu-Cys-Met-Gly-Lys-Ala-Thr-Tyr) with a molecular mass of $1124.35 \mathrm{Da}$ (Table 2). It possesses a net positive charge $(+1)$ at physiological $\mathrm{pH}$ and more hydrophobicity $(40 \%)$ than original Brucin (36\%) (Table 2). The amino acid Gly may be a relative importance amino acid residues in the original peptide, Brucin for its antibacterial activity; which when substituted with Lys, Arg or Pro as in other modified peptide sequences gave net positive or negative charge, resulting in no inhibition of the bacteria growth (Table 2). In addition to the inhibitory activity to S. pyogenes, the enhance inhibitory activity against $S$. epidermidis of M-Brucin may due to the increase in its hydrophobicity, since 
there is evident that antimicrobial activity increases linearly with increases in the peptide hydrophobicity in similar peptides (Rosenfeld et al., 2010). The interaction with the bacterial cell wall should be further investigate to understand the mechanism of its antibacterial action. The near by values of $\mathrm{IC}_{50}$ of $\mathrm{M}$-Brucin towards $S$. pyogenes and $S$. epidermidis as found in penicillin $\mathrm{G}$ and chloramphenicol antibiotics suggests that M-Brucin could have been proposed as possibility for development as an alternative to antibiotics, especially in some patients who are allergic to penicillin.

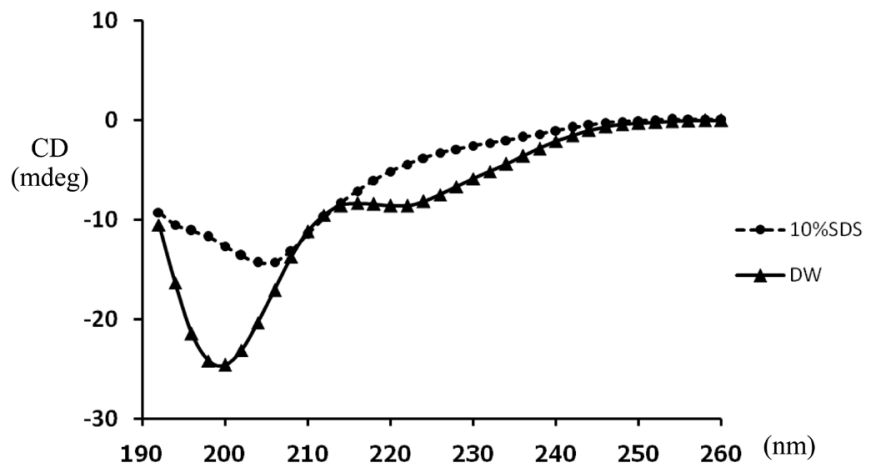

Fig. 3: CD spectra of modified brucin (MB) peptide. The peptide $(0.2 \mathrm{mg} / \mathrm{ml})$ was prepared in distilled water (DW) and $10 \%$ SDS.

\section{CONCLUSION}

Generally, original antibacterial peptides derived from natural source. The active Brucin peptide derived from plant and its amino acid sequence was used as the template to modify and improve its inhibitory activity by using computer program. The candidate peptides were synthesized to test its inhibitory activity and compared to the original peptide (Brucin). M-Brucin (modified-peptide) was confirmed its improvement inhibitory activity against Stap. epidermidis and S. pyogenes and was identified as being as strong as chloramphenicol and penicillin-G while, original peptide (Brucin) has only specific activity against S. pyogenes.

\section{CONFLICT OF INTERESTS}

The authors declare no conflicts of interest.

\section{ACKNOWLEDGEMENT}

This work was supported by the Kasetsart University Research and Development Institute (KURDI). Special thanks to the Department of Biotechnology, Faculty of Science, Ramkhamhaeng University for hosting of the bacterial laboratory and to Dr. Jamorn Somana for suggestions in the manuscript preparation. Emeritus Prof. Dr. M.R. Jisnuson Svasti and Associate Prof. Dr. Sunanta Ratanapo are gratefully acknowledged for careful reading of the manuscript and editorial help.

\section{REFERENCES}

Arpornsuwan T, Punjanon T. Tumor cell- selective antiproliferative effect of the extract from Morinda citrifolia fruits. Phytother Res, 2006; 20 (6): 515-517.

Carapetis JR, Steer AC, Mulholland EK, Weber M. The global burden of group A Streptococcal diseases. Lencet Infect Dis, 2005; 5: 685-694.

Ferrari M, Fornasiero MC, Isetta AM. MTT colorimetric assay for testing macrophage cytotoxicity activity in vitro. J Immunol Methods, 1990; 131: 165-172.

Garnier J, Gibrat JF, Robson B. GOR method for predicting protein secondary structure from amino acid sequence. Methods Enzymol, 1996; 266: 540-530.

Godballe T, Nilsson LL, Peterson PD, Jenssen H. Antimicrobial $\beta$-and $\alpha$-peptoids. Chem Biol Des, 2011; 77:107-116.

Hancock REW, Haney EF. Peptide design for antimicrobial and immunomodulatory applications. Biopolymers, 2013; 100: 572-583.

Imamura M, Wada S, Ueda K, Saito A, Koizumi N, Iwahana $\mathrm{H}$. Mutipeptide precursor structure of acaloleptin A isoforms, antibacterial peptides from the Udo longicorn beetle, Acalolepta luxuriosa. Dev Comp Immunol, 2009; 33: 1120-1127.

Jenssen H, Hamill P, Hancock RE. Peptide antimicrobial agents. Clin Microbiol Rev, 2006; 19: 491-511.

Lingeng L, Dionyssios K, Susan TM, Harvey AR, Ciara B, Emilie MC, Herbert Yu. Functional study of risk loci of stem-cell associated gene lin-28B and associations with disease survival out comes in epithelial ovarian cancer. Carcinogenesis, 2012; 33: 2119-2125.

Michael O. Staphylococcus epidermidis- the 'accidental' pathogen. Nature Rev Micro, 2009; 7: 555-563.

Mitchell TJ. The pathogenesis of streptococcal infections: from tooth decay to Meningitis. Nat Rev Microbial, 2003; 1: 219-230.

National Committee for Clinical Laboratory Standards. Performance Standards for Dilution Antimicrobial Susceptibility Testing for Bacteria that Grow Aerobically, NCCLS document M100-58. Villanova, PA, 1997.

Nikken W, Melvin YSS, Majad K, Zhan-Yuin O, Yi-Yan Y. Rationally designed $\alpha$-helical broad-spectrum antimicrobial peptides with idealized facial amphiphilicity. Macromol Rapid Commun, 2013; 34: 74-80.

Rosenfeld Y, Lev N, Shai Y. Effect of the hydrophobicity to net positive charge ratio on antibacterial and anti-endotoxin activities of structurally similar antimicrobial peptides. Biochemisty, 2010; 49 (5): 853-861.

Sangtanoo P, Choowongkomon K, Surat W, Nitisinprasert S, Kubera A. Antimicrobial peptides of Lactobacillus Salivarius K4 isolated from chicken intestine. ScienceAsia, 2014; 40: 135-140.

Shai Y. Mode of action of membrane active antimicrobial peptide. Biopolymers, 2002; 66: 236-248.

Sornwatana T, Roytrakul S, Wetprasit N, Ratanapo S. Brucin, an antibacterial peptide derived from fruit protein of Fructus Bruceae, Brucea javanica (L.) Merr. Lett Appl Microbiol, 2013; 57(2): 129-136.

Wang G, Li X, Wang Z. APD2: the updated antimicrobial peptide database and its application in peptide design. Nucl Acids Res, 2009; 


\section{7: D 933-937.}

Weinstein MP, Towns ML, Quartey SM, Mirrett S, Reimer LG, Parmigiani G, Reller LB. The clinical significance of positive blood cultures in the 1990s: a prospective comprehensive evaluation of the microbiology, epidemiology, and outcome of bacteremia and fungemia in adults. Clin Inf Dis, 1997; 24: 584-602.

William FP, Osmar NS, Octavio LF. Prediction and rational design of antimicrobial peptide, Protein Structure, Dr. Eshel Faraggi (Ed.), ISBN: 978-953-51-0555-8, 2012.

Wong JH, Ng TB. Sesquin, a potent defensin-like antimicrobial peptide from ground beans with inhibitory activities toward tumor cells and HIV-1 reverse transcriptase. Peptides, 2005; 26: 1120-1126.
Yeamn MR, Yount NY. Mechanisms of antimicrobial peptide action and resistance. Pharmarcol Rev, 2003; 55: 27-55.

\section{How to cite this article:}

Sornwatana T, Arpornsuwan T, Roytrakul S, Wetprasit N M-Brucin, an antibacterial peptide against Staphylococcus epidermidis and Streptococcus pyogenes. J App Pharm Sci, 2018; 8(02): 027032. 